\title{
Synthesis of Benzimidazole Derivatives Containing Schiff Base Exhibiting Antimicrobial Activities
}

\author{
Alam S.A.M. F. ${ }^{1}$, Ahmad T. ${ }^{2}$, Nazmuzzaman M. ${ }^{2}$, Ray S. K. ${ }^{2}$, Sharifuzzaman M. ${ }^{3}$, \\ Karim M. R. ${ }^{3}$, Alam M. G. ${ }^{4}$, Ajam M. M. ${ }^{2}$, Maitra P. ${ }^{2}$, Mandol D. ${ }^{5}$, Uddin M. E. ${ }^{6}$, \\ Ahammed T. ${ }^{4}$ \\ ${ }^{1}$ Dept. of Pharmaceutical Chemistry, Lovely Professional University, Punjab, India \\ ${ }^{2}$ Dept. of Biotechnology and Genetic Engineering, Islamic University, Kushtia, Bangladesh \\ ${ }^{3}$ Dept. of Microbiology, Chittagong University, Chittagong, Bangladesh \\ ${ }^{4}$ Dept. of Microbiology, Gono Bishwabidyalay, Dhaka, Bangladesh \\ ${ }^{5}$ Dept. of Applied Nutrition and Food Technology, Islamic University, Kushtia, Bangladesh \\ ${ }^{6}$ Dept. of Biochemistry and Molecular Biology, Gono Bishwabidyalay, Dhaka, Bangladesh
}

\begin{abstract}
A series of 2-substituted Benzimidazole having imine linkage were synthesized by two step reactions. In the first step, o-phenylenediamine was condensed with p-amino benzoic acid in xylene and poly phosphoric acid to give 2-amino Benzimidazole. In the second step, 2-amino Benzimidazole is treated with different substituted aldehydes and ketones to form substituted Benzimidazole having imine linkage. The synthesized compounds were evaluated for anti-bacterial activity against Staphylococcus aureus and Escherichia coli by tube dilution method. The compounds SAM-2 and SAM-10 were found to be more potent than standard drug vancomycin against Gram (+) ve and Gram (-) ve bacteria. The compounds SAM-4 and SAM-9 had antimicrobial activity comparable to standard drugs against both the microorganisms. The aims of this study to synthesize novel benzimidazole derivatives containing Schiff's base and evaluate the antimicrobial activity of the synthesized derivatives against S. aureus and E. coli.
\end{abstract}

Keywords: Benzimidazole, Schiff base, Antimicrobial activity, Staphylococcus aureus, Synthesized

\section{INTRODUCTION}

Benzimidazole is a heterocyclic aromatic organic compound. It is an important pharmacophore and a fortunate structure in medicinal chemistry. This bicyclic compound consists of the fusion of benzene and imidazole ring ${ }^{[1,20]}$. The general synthesis of benzimidazole involves condensation of phenylenediamine with formic acid. By using different derivative of carboxylic acid, this method is generally able to afford 2-substituted benzimidazoles ${ }^{[5]}$.

The different benzimidazole derivatives are associated with a wide range of biological activities such as anti-cancer ${ }^{[13]}$, anti-viral ${ }^{[21]}$, anti-bacterial ${ }^{[7,9,22]}$, anti-fungal ${ }^{[18]}$, anti-helmintic ${ }^{[23]}$, antiinflammatory ${ }^{[10]}$, anti-histaminic ${ }^{[15]}$, proton pump inhibitor ${ }^{[8]}$, anti-oxidant ${ }^{[2]}$, anti-hypertensive ${ }^{[14]}$ and anti-coagulant ${ }^{[17]}$ properties. Literature review shows that along with the benzimidazole derivatives, 2-substituted ones are found to be pharmacologically more important and hence syntheses of 2-substituted benzimidazoles are the reasonable area of research ${ }^{[4,19]}$. Prevalent biochemical and pharmacological studies have confirmed that its derivatives are capable against a variety of strains of microorganisms ${ }^{[6,11, \text { and } 12]}$.

Imines are formed by the reaction of a primary amine with aldehydes or ketones with the simultaneous removal of water e.g. by azeotropic distillation, by addition of anhydrous sodium sulfate, by addition of molecular sieves or by use of titanium chloride. When one, or both, of reactant is aliphatic, the imine is quite stable and usually known as a Schiff base ${ }^{[5]}$. In case of completely aliphatic reactants, the imines tend to decompose or polymerize; in these cases their further reaction is carried out without delay ${ }^{[5]}$.

The formation of a Schiff base from aldehydes of ketones is a reversible reaction and generally takes place under acid or base catalysis. The formation is generally driven to the completion by separation 
of the product or removal of water or both. Many Schiff bases can be hydrolyzed back to their aldehydes or ketones and amines by aqueous acid or base. The mechanism of formation of Schiff base is another variation on the theme of nucleophilic addition to the carbonyl group. In this case, the nucleophile is the amine. In the first part of the mechanism, the amine reacts with the aldehyde or ketone to give an unstable carbinolamine compound ${ }^{[16]}$.Schiff bases have also exhibited a broad range of biological activities including anti-fungal, anti-bacterial, anti-malarial, anti-proliferative, antiinflammatory, anti-viral, and anti-pyretic properties ${ }^{[3]}$.

\section{MAterials AND Methods}

\subsection{General Methodology}

The experiment was conducted in the Department of Pharmaceutical Chemistry, Lovely Professional University, Punjab, India. The melting points of compounds were determined by capillary method. The slurry for the preparation of TLC plates was prepared by mixing the adsorbent (Silica gel G) in water. The TLC plates were prepared by pouring method. IR spectra were recorded on FTIR spectrophotometer Shimadzu, Singapore as $\mathrm{KBr}$ disks. H-NMR spectra were acquired using a Bruker Avance-2 NMR spectrometer $(400 \mathrm{MHz})$ using TMS as internal standard. The following abbreviations were used to indicate the peak multiplicity: $\mathrm{s}=$ singlet, $\mathrm{d}=$ doublet, $\mathrm{t}=$ triplet, $\mathrm{m}=$ multiplet. ${ }^{1} \mathrm{H}-\mathrm{NMR}$ spectra were assigned relative to the TMS peak at $0.0 \mathrm{ppm}$.

The percentage yield of the reaction was calculated by the following formula:

$$
\text { Percentage Yield }=\frac{\text { Practical yield }}{-------------} \times 100
$$

\subsection{Synthesis of 2-(4-Aminophenyl)-1H-Benzimidazole}

A suspension of polyphosphoric acid $(0.08 \mathrm{~mol})$ in xylene $(0.2 \mathrm{~mol})$ at $60^{\circ} \mathrm{C}, o$-phenylenediamine $(0.03 \mathrm{~mol})$ and 4 -aminobenzoic acid $(0.03 \mathrm{~mol})$ were added. The temperature was raised to $130^{\circ} \mathrm{C}$ for 1 $\mathrm{hr}$ before it was raised to $150^{\circ} \mathrm{C}$ and stirred for $6 \mathrm{~h}$. The reaction mixture was cooled and diluted with hot water with stirring. The hot reaction mixture was filtered through a Buchner funnel and solid was isolated. Mother liquor also afforded additional solid. Both solids were taken in water $(500 \mathrm{ml})$ and neutralized with solid $\mathrm{NaHCO}_{3}$. The yellowish green solid was filtered. These observed characteristics were- Melting point : $297-299^{\circ} \mathrm{C}$, Yield: $51 \%$, Solubility: Soluble in DMSO, Mobile phase - Ethyl acetate: hexane (4:6), $\mathrm{R}_{\mathrm{f}}$ value for $O$-Phenylendiamine- $0.33, \mathrm{R}_{\mathrm{f}}$ value for 2- (4 aminophenyl)- $1 H$-benzimidazole- $0.12, \mathrm{R}_{\mathrm{f}}$ value for 4 -amino benzoic acid- 0.15 .

\subsection{Synthesis of Imine Derivatives of Benzimidazole}

2-(4-aminophenyl)-1H-benzimidazole $(0.002 \mathrm{~mol})$ was mixed with different substituted aldehydes / ketones $(0.002 \mathrm{~mol})$ in $15 \mathrm{ml}$ absolute ethanol. The reaction mixture was refluxed till the completion of reaction (as indicated by TLC using silica as stationary phase and (Toluene: Ethyl acetate: Formic acid: 5:4:1 as mobile phase). Then the reaction mixture was concentrated and kept overnight for crystallization. The solid separated was filtered and recrystallized from $95 \%$ ethanol.
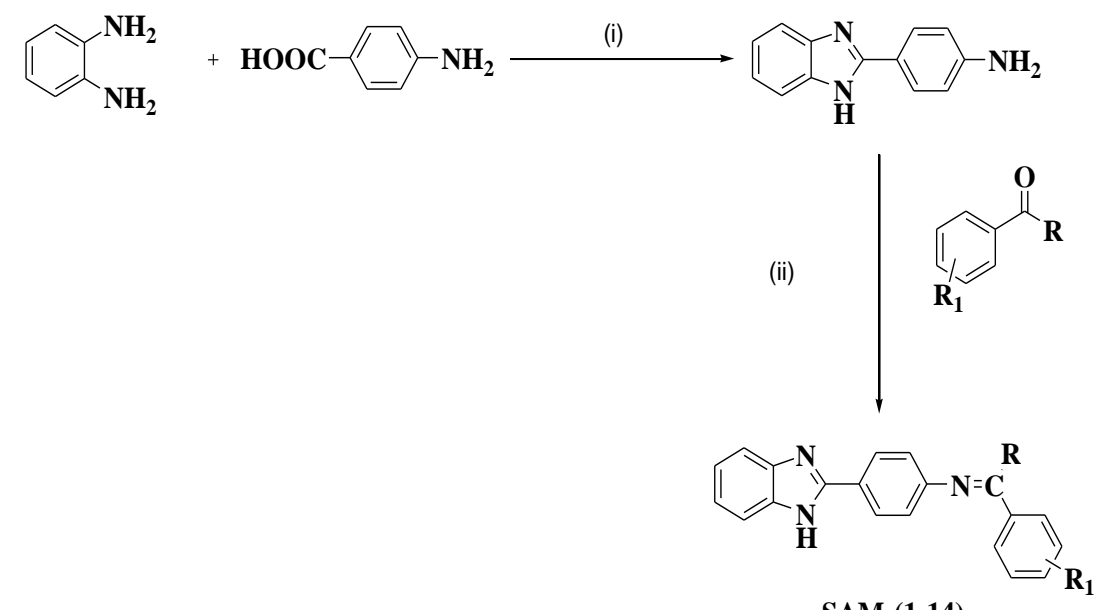

SAM-(1-14)

Scheme: Reagents: (i) PPA/Xylene, $150^{\circ} \mathrm{C}$, 6hr Reflux (ii) Ethanol 
Table1. List of synthesized benzimidazole derivatives containing Schiff base

\begin{tabular}{|c|c|c|c|}
\hline Serial No. & Compound codes & $\mathrm{R}$ & $\mathrm{R}_{1}$ \\
\hline 1 & $\mathrm{SAM}-1$ & $-\mathrm{H}$ & $-\mathrm{Cl}$ \\
\hline 2 & $\mathrm{SAM}-2$ & $-\mathrm{H}$ & $4-\mathrm{F}$ \\
\hline 3 & $\mathrm{SAM}-3$ & $-\mathrm{H}$ & $4-\mathrm{NO}_{2}$ \\
\hline 4 & $\mathrm{SAM}-4$ & $-\mathrm{H}$ & $2-\mathrm{NO}_{2}$ \\
\hline 5 & $\mathrm{SAM}-5$ & $-\mathrm{H}$ & $4-\mathrm{NO}_{2}$ \\
\hline 6 & $\mathrm{SAM}-6$ & $-\mathrm{CH}_{3}$ & $-\mathrm{H}$ \\
\hline 7 & $\mathrm{SAM}-7$ & $-\mathrm{CH}_{3}$ & $4-\mathrm{OH}$ \\
\hline 8 & $\mathrm{SAM}-8$ & $-\mathrm{H}$ & $4-\mathrm{OH}$ \\
\hline 9 & $\mathrm{SAM}-9$ & $-\mathrm{CH}_{3}$ & $2-\mathrm{OH}$ \\
\hline 10 & $\mathrm{SAM}-10$ & $-\mathrm{H}$ & $4-\mathrm{OCH}$ \\
\hline 11 & $\mathrm{SAM}-11$ & $-\mathrm{H}$ & $4-\mathrm{Cl}$ \\
\hline 12 & $\mathrm{SAM}-12$ & $-\mathrm{H}$ & $3-\mathrm{OCH}-4-\mathrm{OH}$ \\
\hline 13 & $\mathrm{SAM}-13$ & $-\mathrm{H}$ & $2,4-\mathrm{OH}$ \\
\hline 14 & $\mathrm{SAM}-14$ & $-\mathrm{CH}_{3}$ & \\
\hline
\end{tabular}

N-(2-chlorobenzylidene)-4-(1H-benzo[d]imidazol-2-yl)benzenamine (SAM-1):Melting point : 326$330{ }^{\circ} \mathrm{C}$, Yield : 50\%, Solubility : Soluble in DMSO, $\mathrm{R}_{\mathrm{f}}$ value for 2-(4-aminophenyl)-1Hbenzimidazole- $0.46, \mathrm{R}_{\mathrm{f}}$ value for Compound (SAM-1)- 0.26, $\mathrm{R}_{\mathrm{f}}$ value for 2 - Chlorobenzaldehyde0.82. IR (KBr) cm-1; $3344(\mathrm{~N}-\mathrm{H}), 3219$ (aromatic C-H), 3059(C-H imine linkage), $1627(\mathrm{C}=\mathrm{N}), 1600$ and 1462 (aromatic $\mathrm{C}=\mathrm{C}) ; 1 \mathrm{H}-\mathrm{NMR}$

4-(1H-benzo[d]imidazol-2-yl)-N-benzyl idene benzenamine (SAM-2): Melting point: $328-330{ }^{\circ} \mathrm{C}$, Yield: $48 \%$, Solubility: Soluble in DMSO, $\mathrm{R}_{\mathrm{f}}$ value for 2-(4-aminophenyl)-1H-benzimidazole- 0.47 , $\mathrm{R}_{\mathrm{f}}$ value for Compound (SAM-2) $-0.58, \mathrm{R}_{\mathrm{f}}$ value for Benzaldehyde- 0.78 .

N-(4-fluorobenzylidene)-4-(1H-benzo[d]imidazol-2-yl)benzenamine (SAM-3):Melting point : $287-291$ ${ }^{\circ} \mathrm{C}$, Yield : 62\%, Soluble in DMSO, $\mathrm{R}_{\mathrm{f}}$ value for 2-(4-aminophenyl)- $1 H$-benzimidazole- $0.47, \mathrm{R}_{\mathrm{f}}$ value for Compound (SAM-3)- 0.80, $\mathrm{R}_{\mathrm{f}}$ value for 4-Flurobenzaldehyde- 0.89 .

N-(4-nitrobenzylidene)-4-(1H-benzo[d]imidazol-2-yl)benzenamine (SAM-4):Melting point : 270-280 ${ }^{\circ} \mathrm{C}$, Yield : $65 \%$, Soluble in DMSO, $\mathrm{R}_{\mathrm{f}}$ value for 2-(4-aminophenyl)-1H-benzimidazole- $0.46, \mathrm{R}_{\mathrm{f}}$ value for Compound (SAM-4)- 0.64, $\mathrm{R}_{\mathrm{f}}$ value for 4-Nitrobenzaldehyde -0.76 .

N-(2-nitrobenzylidene)-4-(1H-benzo[d]imidazol-2-yl) benzenamine (SAM-5):Melting point : 284-289 ${ }^{\circ} \mathrm{C}$, Yield : $61 \%$, Soluble in DMSO, $\mathrm{R}_{\mathrm{f}}$ value for 2-(4-aminophenyl)- $1 H$-benzimidazole- $0.46, \mathrm{R}_{\mathrm{f}}$ value for Compound (SAM-5)- 0.48, $\mathrm{R}_{\mathrm{f}}$ value for 2-Nitrobenzaldehyde -0.77 .

4-(1H-benzo[d]imidazol-2-yl)-N-(1-(4-nitrophenyl)ethylidene) benzenamine (SAM-6):Melting point : 286-291, Yield : 50\%, Soluble in DMSO, $\mathrm{R}_{\mathrm{f}}$ value for 2-(4-aminophenyl)- $1 H$-benzimidazole- $0.48, \mathrm{R}_{\mathrm{f}}$ value for Compound (SAM-6)- 0.37, $\mathrm{R}_{\mathrm{f}}$ value for 4-Nitroacetophenone -0.81 .

4-(1H-benzo[d]imidazol-2-yl)-N-(1-phenylethylidene) benzenamine (SAM-7): Melting point: 276-281 ${ }^{\circ} \mathrm{C}$, Yield: $45 \%$, Soluble in DMSO, $\mathrm{R}_{\mathrm{f}}$ value for 2-(4-aminophenyl)-1H-benzimidazole- $0.46, \mathrm{R}_{\mathrm{f}}$ value for Compound (SAM-7)- 0.26, $\mathrm{R}_{\mathrm{f}}$ value for Acetophenone -0.84 .

4-((4-(1H-benzo[d]imidazol-2-yl) phenylimino) methyl) phenol (SAM-8):Melting point : 284-289 ${ }^{\circ} \mathrm{C}$, Yield : $50 \%$, Soluble in DMSO, $\mathrm{R}_{\mathrm{f}}$ value for 2-(4-aminophenyl)-1H-benzimidazole $-0.45, \mathrm{R}_{\mathrm{f}}$ value for Compound (SAM-8)- 0.26, $\mathrm{R}_{\mathrm{f}}$ value for 4-Hydroxybenzaldehyde -0.70 .

4-(1-(4-(1H-benzo[d]imidazol-2-yl)phenylimino)ethyl) phenol (SAM-9):Melting point : $284-289{ }^{\circ} \mathrm{C}$, Yield : $55 \%$, Soluble in DMSO, $\mathrm{R}_{\mathrm{f}}$ value for 2-(4-aminophenyl)- $1 H$-benzimidazole- $0.46, \mathrm{R}_{\mathrm{f}}$ value for Compound (SAM-9)- 0.71, $\mathrm{R}_{\mathrm{f}}$ value for 4-Hydroxyacetophenone- 0.80 .

2-((4-(1H-benzo[d]imidazol-2-yl) phenylimino) methyl) phenol (SAM-10):Melting point : $284-288^{\circ} \mathrm{C}$, Yield : $62 \%$, Soluble in DMSO, $\mathrm{R}_{\mathrm{f}}$ value for 2-(4-aminophenyl)-1H-benzimidazole- $0.44, \mathrm{R}_{\mathrm{f}}$ value for Compound (SAM-10)- 0.65, $\mathrm{R}_{\mathrm{f}}$ value for 2-Hydroxybenzaldehyde- 0.78 .

N-(4-methoxybenzylidene)-4-(1H-benzo[d]imidazol-2-yl)benzenamine (SAM-11):Melting point : 274$278^{\circ} \mathrm{C}$, Yield : 54\%, Soluble in DMSO, $\mathrm{R}_{\mathrm{f}}$ value for 2-(4-aminophenyl)- $H$-benzimidazole- $0.47, \mathrm{R}_{\mathrm{f}}$ value for Compound (SAM-11)- 0.64, $\mathrm{R}_{\mathrm{f}}$ value for 4-Methoxybenzaldehyde- 0.72 
$N$-(4-chlorobenzylidene)-4-(1H-benzo[d]imidazol-2-yl)benzenamine (SAM-12):Melting point : 274$278{ }^{\circ} \mathrm{C}$, Yield : $51 \%$, Soluble in DMSO, $\mathrm{R}_{\mathrm{f}}$ value for 2-(4-aminophenyl)- $1 H$-benzimidazole- $0.46, \mathrm{R}_{\mathrm{f}}$ value for Compound (SAM-12)- $0.58, \mathrm{R}_{\mathrm{f}}$ value for 4-Chlorobenzaldehyde -0.88 .

4-((4-(1H-benzo[d]imidazol-2-yl) phenylimino) methyl) -2 methoxy phenol. (SAM-13):Melting point : 274-278 ${ }^{\circ} \mathrm{C}$, Yield : 64\%, Soluble in DMSO, $\mathrm{R}_{\mathrm{f}}$ value for 2-(4-aminophenyl)-1H-benzimidazole$0.46, \mathrm{R}_{\mathrm{f}}$ value for Compound (SAM-13)- 0.23, $\mathrm{R}_{\mathrm{f}}$ value for Vanillin- 0.82 .

4-(1-(4-(1H-benzo[d]imidazol-2-y) phenylimino)ethyl)benzene-1,3-diol (SAM-14):Melting point : 274-278 ${ }^{\circ} \mathrm{C}$, Yield : $64 \%$, Soluble in DMSO, $\mathrm{R}_{\mathrm{f}}$ value for 2-(4-aminophenyl)-1H-benzimidazole$0.45, R_{\mathrm{f}}$ value for Compound (SAM-14)- $0.64, \mathrm{R}_{\mathrm{f}}$ value for 2,4 -Dihydroxyacetophenone -0.82 .

\subsection{Estimation of Anti-Bacterial Activity}

The anti-bacterial activity of compounds was studied by employing a tube-dilution method, using two different culture media: Mueller-Hinton broth and Luria Bertania (LB). Compounds were dissolved in DMSO (10\% of the final volume) and diluted with culture broth to a concentration of $2 \mathrm{mg} / \mathrm{mL}$. Further 1:2 serial dilutions were performed by addition of culture broth to reach concentrations ranging from 2 to $0.0156 \mathrm{mg} / \mathrm{mL}, 100 \mu \mathrm{L}$ of each dilution were distributed in 96 well plates/tubes, as well as a sterility control and a growth control (containing culture broth plus DMSO, without antimicrobial substance).

All experiments were performed in triplicate and the micro dilution trays were incubated at $36^{\circ} \mathrm{C}$ for $18 \mathrm{~h}$. Bacterial growth was detected former by optical density and after by addition of $20 \mu \mathrm{L}$ of an INT alcoholic solution $(0.5 \mathrm{mg} / \mathrm{mL})$. The trays were again incubated at $36^{\circ} \mathrm{C}$ for $30 \mathrm{~min}$, and in those wells, where bacterial growth occurred. MIC values were defined as the lowest concentration of each compound, which completely inhibited microbial growth ${ }^{[24]}$.

\section{RESULTS AND DISCUSSION}

\subsection{4-(1H-Benzo[d]Imidazol-2-yl)- $N$-Benzylidenebenzenamine (SAM-2)}

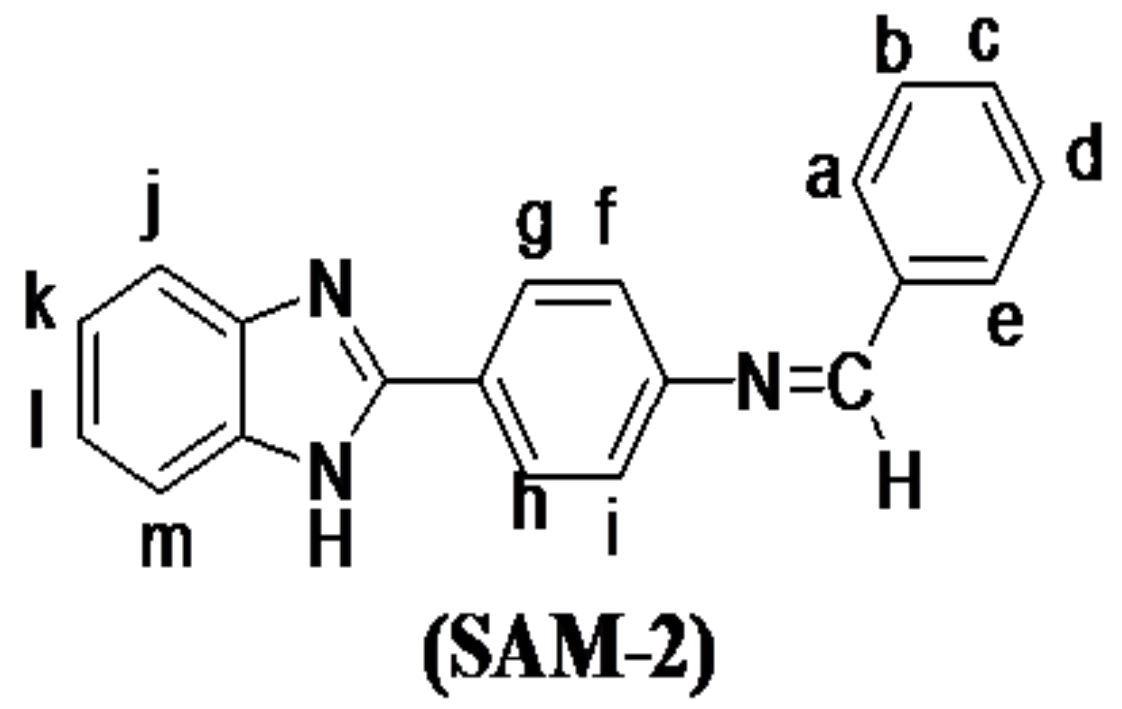

\subsection{IR Spectra}

IR spectra of the compound showed one medium intensity band of secondary N-H stretching vibrations at $3473 \mathrm{~cm}^{-1}$. A medium band at $3385 \mathrm{~cm}^{-1}$ indicated aromatic $\mathrm{C}-\mathrm{H}$ stretching vibrations. A weak band observed at $1641 \mathrm{~cm}^{-1}$ due to the presence of $\mathrm{C}=\mathrm{N}$. Two bands at $1610 \mathrm{~cm}^{-1} \& 1464 \mathrm{~cm}^{-1}$ indicated the presence of $\mathrm{C}=\mathrm{C}$ ring structure. A medium band observed at $1200 \mathrm{~cm}^{-1}$ due to the presence of C-N. The N-H bending vibrations were observed at $1512 \mathrm{~cm}^{-1}$. The para disubstituted ring was confirmed by a band at $940 \mathrm{~cm}^{-1}$ (fig 1). 


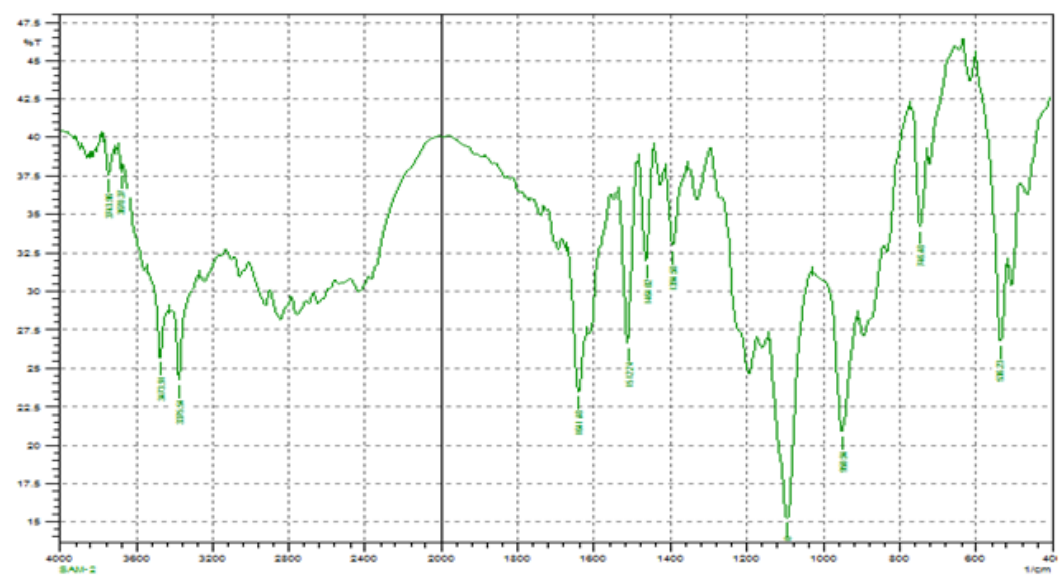

Fig1. IR Spectra of 4-(1H-benzo[d]imidazol-2-yl)-N-benzylidenebenzenamine

\subsection{NMR Spectra}

NMR spectra of the compound showed a triplet at 7.29 indicate three aromatic methine protons designated as b, c \& d. One triplet were observed at 7.62 due to the presence of two aromatic methine protons designated as a \& e. A doublet at 6.7 indicates two aromatic methine protons designated as $\mathrm{f}$ $\&$ i. One triplet was observed at 7.2 due to the presence of two aromatic methine protons designated as $\mathrm{g} \& \mathrm{~h}$. Similarly another doublet was observed at 8.27 indicate two aromatic methine protons designated as $\mathrm{j} \& \mathrm{~m}$. One triplet was observed at 7.96 due to the presence of two aromatic methine protons designated as $\mathrm{k} \& \mathrm{l}$. A singlet was observed at 8.39 due to the aliphatic methine proton designated as $\mathrm{N}=\mathrm{CH}$. A singlet was observed at 9.69 due to the $\mathrm{N}-\mathrm{H}$ proton of the benzimidazole ring (fig 2).

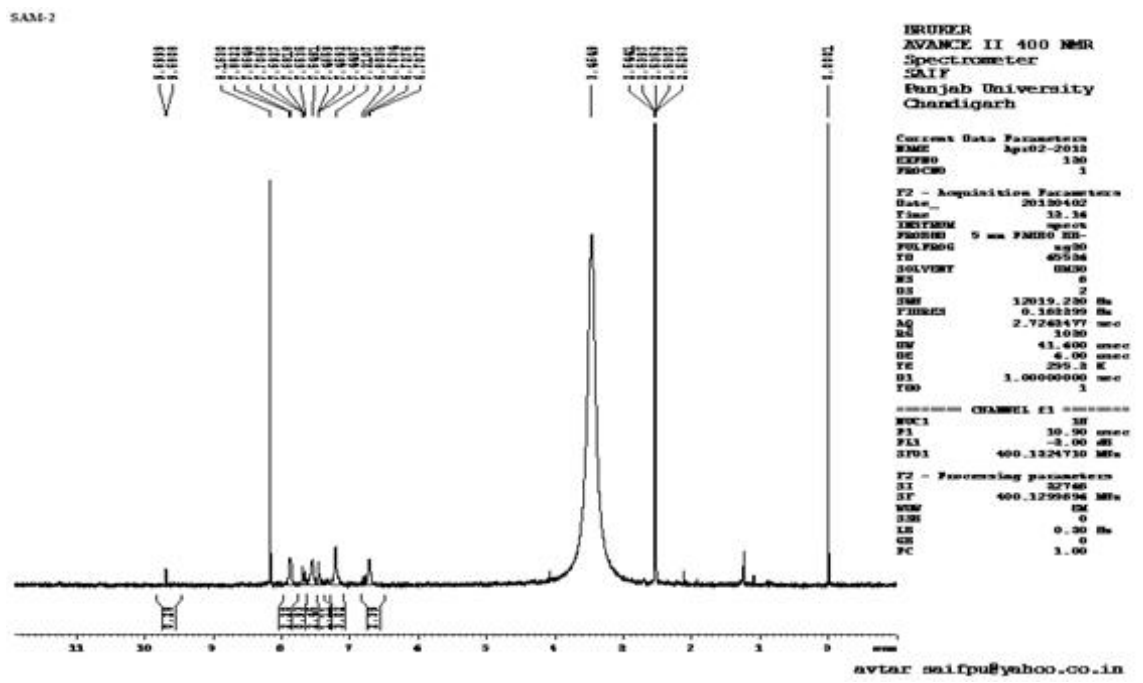

Fig2. NMR Spectra of 4-(1H-benzo[d]imidazol-2-yl)-N-benzylidenebenzenamine

\subsection{Anti-Microbial Screening of the Synthesized Compounds}

The synthesized compounds were screened for their anti-bacterial activity using micro dilution method against $S$. aureus \& E. coli. The reference standard and control used vancomycin and DMSO respectively. The compounds SAM-2, SAM-4, SAM-9 \& SAM-10 were found to be most promising antimicrobial agents among the synthesized compound (table 2).

Table2. MIC values $(\mu \mathrm{g} / \mathrm{ml})$ of benzimidazole derivatives against gram positive \& gram negative bacteria

\begin{tabular}{|c|c|c|}
\hline Compound & Staphylococcus aureus Gram (+ve) & Escherichia coli Gram (-ve) \\
\hline SAM- 1 & 29 & 25 \\
\hline SAM- 2 & 10 & 13 \\
\hline SAM- 3 & 52 & 46 \\
\hline SAM- 4 & 21 & 17 \\
\hline SAM- 5 & 31 & 29 \\
\hline SAM- 6 & 44 & 55 \\
\hline
\end{tabular}


Alam S.A.M. F. et al.

\begin{tabular}{|c|c|c|}
\hline \hline SAM- & 58 & 38 \\
\hline SAM- 8 & 51 & 29 \\
\hline SAM- 9 & 21 & 18 \\
\hline SAM- 10 & 10 & 11 \\
\hline SAM- 11 & 38 & 42 \\
\hline SAM- 12 & 32 & 30 \\
\hline SAM- 13 & 60 & 45 \\
\hline SAM- 14 & 50 & 39 \\
\hline Vancomycin & 17 & 16 \\
\hline DMSO & 00 & 00 \\
\hline
\end{tabular}

\subsection{Structure Activity Relationship Studies}

Structure activity relationship (SAR) studies revealed that different substitutions on the benzimidazole schiff bases and its azetidinone and thiazolidinone derivatives exerted varied biological activities. The electronic nature of the substituent groups at 4' positions in the benzimidazole nucleus, 7" azetidinone and 2 "' thiazolidinone led to significant variation in antimicrobial activity. Among the series of compounds substituted by electron-withdrawing (-NO2 and - $\mathrm{Cl})$ and electron-donating (-OCH3, - $\mathrm{OH}$ and $-\mathrm{CH} 3$ ) groups are enhanced biological activity.

\section{Conclusion}

A series of benzimidazole derivatives having imine linkage were synthesized by using ophenylenediamine as starting material. In first step, o-phenylenediamine is treated with 4-amino benzoic acid to give 2-aminobenzimidazole which was then treated with different substituted aldehydes or ketones to give benzimidazole containing Schiff base. The synthesized compounds were screened for anti-microbial activity against Gram (+) ve (Staphylococcus aureus) and Gram (-) ve (Escherichia coli) bacteria. The compound SAM-2, SAM-4, SAM-9 \& SAM-10 had MIC values in the range of $10-21 \mu \mathrm{g} / \mathrm{ml}$ while the standard drug vancoycin had MIC value of $17 \mu \mathrm{g} / \mathrm{ml}$.

\section{ACKNOWLEDGEMENTS}

This research was financially supported with proper guidance and helping for data analysis in the Department of Pharmaceutical Chemistry, Lovely Professional University, Punjab, India. Heartiest thanks to the authority of Lovely Professional University for helping us to conduct the research work.

\section{REFERENCES}

[1] Aarons SJ, Sutherland IW, Chakrabarty AM and Gallagher MP (1997). A novel gene, algk, from the alginate biosynthetic cluster of pseudomonas aeruginosa. Microbiol., 143: 641-652

[2] Ates Z, AlagozKus C and Coban T (2005). Synthesis and antioxidant properties of novel benzimidazoles containing substituted indole or 1, 1, 4, 4-tetramethyl-1, 2, 3, 4-tetrahyddrnapht halene fragments. J. Enzyme Inhib. Med. Chem., 20: 325-331

[3] Dhar D and Taploo CL (1982). Schiff bases and their application. J. Sci. Ind. Res. 41: 501-506

[4] Foks H, Pancechowska-Ksepko D, Kuzmierkiewicz W, Zwolska Z, Janowiec M and Augustynowicz-Kopec E (2006). Synthesis and antibacterial activity of 1H-pyrazolo [3, 4-b] pyrazine and -pyridine derivatives. Farmaco., 42: 611-614

[5] Funrniss BS, Hannaford AJ, Smith PWG and TatchellAR (2008). Aliphatic Compounds. In The Vogel's Textbook of Practical Organic Chemistry, 5th ed. Dorling Kindersley Pvt. Ltd., India pp 780-784

[6] Goker H, Kus C, Boykin DW, Yildiz S and Altanlar N (2002). Synthesis of some new 2substituted-phenyl-1H-benzimidazole-5-carbonitriles and their potent activity against Candida species. Bioorg. Med. Chem., 10: 2589-2596

[7] Goker H, Tuncbilek M, Ayhan G and Altanlar N (1998). Synthesis of some new benzimidazole carboxamides and evaluation of their antimicrobial activity. Farmaco., 53: 415-420

[8] Horn J. (2000). The proton-pump inhibitors Similarities and differences. Clin.Ther., 22: 266-280

[9] Hubschwerlen C, Pflieger P, Specklin JL, Gubernator K, Gmunder H, Angehrn P and Kompis I (1992). Pyrimido [1, 6-a] benzimidazoles: a new class of DNA gyrase inhibitors. J. Med. Chem., 35: 1385-1392 
[10] Iemura R, Kawashima T, Fukuda T, Ito K and Tsukamoto G (1986). Synthesis of 2-(4substituted-1-piperazinyl) benzimidazoles as H1-antihistaminic agents. J. Med. Chem., 29 : $1178-1183$

[11] Khalafi-Nezhad A, Rad MNS, Mohbatkar H, Asrari Z and Hemmateenejad B (2005). Design, synthesis, antibacterial and QSAR studies of benzimidazole and imidazole chloro aryloxyalkyl derivatives. Bioorg. Med. Chem., 13: 1931-1938

[12] Klimesova V, Koci J, Pour M, Stachel J, Waisser K and Kaustova J (2002). Synthesis and preliminary evaluation of benzimidazole derivatives as antimicrobial agents. Eur. J. Med. Chem., 37: 409-418

[13] Kruse LI, Ladd DL, Harrsch PB, McCabe FL, Mong SM, Faucette L and Johnson R (1989). Synthesis, tubulin binding, antineoplastic evaluation, and structure-activity relationship of oncodazole analogues. J. Med. Chem., 32: 409-417

[14] Kubo K, Kohara Y, Yoshimura Y, Inada Y, Shibouta Y, Furukawa Y, Kato T Nishikawa, K and Naka T (1993). Nonpeptide angiotensin II receptor antagonists. Synthesis and biological activity of potential prodrugs of benzimidazole-7-carboxylic acids. J. Med. Chem., 36: 2343-2349

[15] Labanauskas LK, Brukstus AB, Gaidelis PG, Buchinskaite VA, Udrenaite EB and Dauksas VK (2000). Synthesis and Anti-inflammatory activity of new derivatives of 6-benzoil-1,4 benzodioxane. Pharm. Chem. J., 34: 353-355

[16] Lundon GM (2002). Organic Chemistry. 4th edition Addison-Wesley, California. pp, 872-874.

[17] Mederski WKR, Dorsch D, Anzali S, Gleitz J, Cezanne B and Tsaklakidis C 2004 Synthesis and In-vivo Evaluation of Carbonyl-amide Linkage Based New Benzimidazole Derivatives. Bioorg. Med. Chem. Lett., 14: 3763-3769.

[18] Pawar NS, Dalal DS, Shimpi SR and Mahulikar PP (2004). Studies of antimicrobial activity of $\mathrm{N}$-alkyl and N-acyl 2-(4-thiazolyl)-1H-benzimidazoles. Eur. J. Pharm. Sci., 21: 115-118

[19] Preston PN (1980). Benzimidazoles and Congeneric Tricyclic Compounds Part 2. Wiley Interscience, New York, (Chapter10) pp 531

[20] Selvam P, Radhika PP, Janagaraj S and Kumar AS (2011). Synthesis of novel 2-substituted benzimidazole derivatives as potential anti microbial agents. RIB, 2: 50-57

[21] Townsend LB (1996). WO Patent 96/07646

[22] Tuncbilek M, Goker M, Ertan R, Eryigit R, Kendi E and Altanlar N (1997). Synthesis and antimicrobial activity of some new aniline benzimidazoles. Arch. Pharm. Pharm. Med.Chem., 330: $372-376$

[23] Valdez J, Cedillo R, Hernandez-Campos A, Yepez L, Hernandez-Luis F, Navarrete-Vazquez G, Tapia A, Cortes R, Hernandez M and Castillo R (2002). Synthesis and anti parasitic activity of 1H-benzimidazole derivatives. Bioorg. Med. Chem. Lett., 12: 2221-2224

[24] Valgas C, Souza SMD, Smania EFA and Smania AJ (2007). Screening methods to determine antibacterial activity of natural products. Braz. J. Microbiol., 38: 1517-1522 